\title{
Impact of age on efficacy of postoperative oxaliplatin-based chemotherapy in patients with rectal cancer after neoadjuvant chemoradiotherapy
}

\author{
Xuan-zhang Huang 1,2,*, Peng Gao ${ }^{2, *}$, Yong-xi Song ${ }^{2}$, Jing-xu Sun ${ }^{2}$, Xiao-wan Chen ${ }^{2}$, \\ Jun-hua Zhao', Bin $\mathrm{Ma}^{2}$, Jun Wang ${ }^{2}$, Zhen-ning Wang' \\ ${ }^{1}$ Department of Chemotherapy and Radiotherapy, the Second Affiliated Hospital and Yuying Children's Hospital of Wenzhou \\ Medical University, Lucheng District, Wenzhou City 325027, P.R. China \\ ${ }^{2}$ Department of Surgical Oncology and General Surgery, the First Hospital of China Medical University, Heping District, \\ Shenyang City 110001, P.R. China \\ *These authors have contributed equally to this work \\ Correspondence to: Zhen-ning Wang, e-mail: josieon826@sina.cn
}

Keywords: rectal cancer, adjuvant chemotherapy, age, elderly, SEER program

Received: September 25, 2015

Accepted: January 31, 2016

Published: February 21, 2016

\section{ABSTRACT}

Background: Clinical practice guidelines focusing on age-related adjuvant chemotherapy for rectal cancer are currently limited. The present study aimed to explore the impact of age on the efficacy of adjuvant oxaliplatin-based chemotherapy in patients with rectal cancer after neoadjuvant chemoradiotherapy.

Methods: We performed a retrospective cohort analysis using data from the Surveillance, Epidemiology, and End Results-Medicare-linked database from 1992-2009. We enrolled patients with yp stages I-III rectal cancer who received neoadjuvant chemoradiotherapy and underwent curative resection. The age-related survival benefit of adding oxaliplatin to adjuvant 5-fluorouracil (5-FU) chemotherapy was evaluated using Kaplan-Meier survival analysis with propensity score-matching and Cox proportional hazards models.

Results: Comparing the oxaliplatin group with the 5-FU group, there were significant interactions between age and chemotherapy efficacy in terms of overall survival (OS) ( $p$ for interaction $=0.017$ ) among patients with positive lymph nodes $(y p N+)$. Adding oxaliplatin to $5-\mathrm{FU}$ could prolong survival in patients aged $<73$ years and ypN+ category, and but did not translate into survival benefits in patients aged $\geq 73$ years and ypN+ category. No significant interactions were observed among ypN- patients, and oxaliplatin did not significantly improve OS, regardless of age.

Conclusions: In patients with rectal cancer who have already received neoadjuvant chemoradiotherapy and undergone curative resection, adding oxaliplatin to 5 -FU could prolong 05 in patients aged $<73$ years and ypN+ category. However, adding oxaliplatin did not translate into survival benefits in patients age $\geq 73$ years and ypN+ category, or in ypN- patients.

\section{INTRODUCTION}

Rectal cancer is one of the most common diagnosed cancers worldwide, with high morbidity [1]. The introduction of multidisciplinary treatments with adjuvant chemoradiotherapy and total mesorectal excision has contributed to improved survival benefits in patients with rectal cancer [2-4]. However, its high mortality and poor prognosis, mainly associated with high rates of recurrence and metastasis, remain challenges for both patients and oncologists $[5,6]$. Preoperative neoadjuvant chemoradiotherapy is regarded as the standard treatment for locally-advanced rectal cancer. The National Comprehensive Cancer Network (NCCN) Clinical Practice Guidelines currently recommend adjuvant 5-fluorourcil (5-FU)-based chemotherapy for the treatment of rectal cancer with positive lymph nodes (ypN+) [7].

Although several studies have evaluated the impact of age on the efficacy of adjuvant chemotherapy in patients with rectal cancer, it remains debatable if 
treatment recommendations for adjuvant chemotherapy should consider age as a factor [8-10]. A lack of high-level evidence means that there is currently no uniform consensus regarding the impact of age on the efficacy of adjuvant chemotherapy. The latest NCCN Guidelines for Older Adult Oncology take account of age in terms of adjuvant chemotherapy in rectal cancer patients, but the age-related cut-off points have not been validated [11]. Furthermore, the effect of age on adjuvant chemotherapy in elderly patients is usually extrapolated from younger patients, because clinical guidelines tend to be based on studies from which elderly patients were often excluded $[12,13]$.

Clinically, age is an important factor affecting the choice of adjuvant chemotherapy in patients with rectal cancer, because elderly patients are more likely to have high comorbidity and poor performance status, which may increase treatment-related complications or death, thus outweighing the survival benefits $[14,15]$. Indeed, studies have reported that the life expectancy of rectal cancer patients is related to age and concomitant comorbidities [16-18]. Age-related decisions about the use of adjuvant chemotherapy in patients with rectal cancer are thus a difficult and complex process, considering the balance between the likely risks and survival benefits.

The purpose of the present study was to explore the impact of age on the efficacy of adjuvant oxaliplatinbased chemotherapy in patients with rectal cancer who had already received neoadjuvant chemoradiotherapy.

\section{RESULTS}

\section{Patient characteristics}

Our study comprised 763 patients with rectal cancer who received neoadjuvant chemoradiotherapy recommended by the NCCN. The detailed baseline characteristics of patients are presented in Table 1. Details of race, marital status, median household income, level of education, histologic type, and intestinal perforation were not presented in Table 1, because the SEER-Medicare rules require that cell sizes less than eleven in a table must be suppressed.

\section{Overall comparison of oxaliplatin and 5-FU groups}

According to univariate analysis, the addition of oxaliplatin did not significantly improve OS (hazard ratio $[\mathrm{HR}]=0.883,95 \%$ confidence interval $[\mathrm{CI}]=0.634-1.230$, $p=0.462$ ) compared with 5-FU. We modeled the interaction between age and the efficacy of oxaliplatin using age as a continuous variable and found no significant interaction in terms of OS $(p=0.719)$. Compared with patients in the 5-FU group, patients in the oxaliplatin group experienced significantly higher rates of most adverse events including neutropenia $(30.04 \%$ vs 8.52 , $\Delta \%=21.52 \%, p<0.001)$, nausea or vomiting $(30.04 \%$ vs $13.33, \Delta \%=16.71 \% p<0.001)$, dehydration $(18.39 \%$ vs $10.19, \Delta \%=8.20 \%, p=0.002)$, and thrombocytopenia $(\Delta \%=7.49 \%, p<0.001)$. Furthermore, elderly patients who received oxaliplatin had significantly higher incidence of acute renal failure compared with younger patients $(\Delta \%=7.27 \%, p=0.010)$, while elderly patients had slightly higher incidences of infection $(\Delta \%=4.17 \%)$, nausea or vomiting $(\Delta \%=1.22 \%)$, dehydration $(\Delta \%=4.21 \%)$, diarrhea $(\Delta \%=1.14 \%)$, thrombocytopenia $(\Delta \%=3.41 \%)$, ischemic heart disease $(\Delta \%=3.64 \%)$, congestive heart failure $(\Delta \%=1.78 \%)$, and cardiac dysrhythmia $(\Delta \%=3.22 \%)$, though the differences were not significant. The detailed chemotherapy-related adverse events are summarized in Supplementary Table 1.

\section{Comparison of ypN+oxaliplatin and 5-FU groups}

We also determined the impact of age on the efficacy of chemotherapy among patients with ypN+ category. In univariate analysis, the addition of oxaliplatin did not significantly improve OS (HR $=0.697,95 \%$ $\mathrm{CI}=0.443-1.097, p=0.119$; Figure 1A) compared with the 5-FU group. Modeling age as a continuous variable, there was a marginally significant interaction between age and the efficacy of oxaliplatin in terms of OS ( $p$ for interaction $=0.082$ ).

The results of STEPP analysis showed that the efficacy of chemotherapy in terms of OS was reversed at age 73 years; the addition of oxaliplatin improved OS compared with 5-FU alone in patients younger than 73 years, but there was no obvious benefit among patients aged $\geq 73$ years (Figure 2). Modeling age as a dichotomous variable (age $\geq 73$ years and $<73$ years), there was a significant interaction between age and efficacy of chemotherapy in terms of OS ( $p$ for interaction $=0.017$ ).

Kaplan-Meier unadjusted survival analysis stratified by age ( $<73$ and $\geq 73$ years) was used to compare survival between the oxaliplatin and 5-FU groups and produced results consistent with those of the STEPP method. Oxaliplatin significantly improved OS in patients younger than 73 years $(\mathrm{HR}=0.411,95 \%$ $\mathrm{CI}=0.206-0.818, p$ for log-rank $=0.009$, Figure 1B), but not in those aged $\geq 73$ years $(\mathrm{HR}=1.229,95 \%$ $\mathrm{CI}=0.670-2.255, p$ for log-rank $=0.501$, Figure $1 \mathrm{C}$ ), compared with the 5-FU group. Moreover, PS-matched cohorts based on related variables were generated for survival analysis, and the difference in OS between the two treatment groups among patients aged $<73$ years remained significant $(\mathrm{HR}=0.409,95 \% \mathrm{CI}=0.196-0.856$, $p=0.018$, Figure $3 \mathrm{~A}$ ), while the difference among patients aged $\geq 73$ years remained insignificant $(\mathrm{HR}=0.805,95 \%$ $\mathrm{CI}=0.376-1.721, p=0.576$, Figure $3 \mathrm{~B})$. 
Table 1: Clinicopathologic features of patients with different chemotherapy regimens

\begin{tabular}{|c|c|c|c|}
\hline & 5-FU & Oxaliplatin & $P$ value \\
\hline Gender & & & 0.858 \\
\hline Male & 321 & 131 & \\
\hline Female & 219 & 92 & \\
\hline Age at diagnosis, years & & & 0.001 \\
\hline $66-70$ & 184 & 105 & \\
\hline $71-75$ & 175 & 70 & \\
\hline$>75$ & 181 & 48 & \\
\hline Residence location & & & 0.025 \\
\hline Big Metro & 261 & 127 & \\
\hline Metro or Urban & 199 & 77 & \\
\hline Less Urban or Rural & 80 & 19 & \\
\hline Year of diagnosis & & & $<0.001$ \\
\hline $1992-2000$ & 125 & 0 & \\
\hline $2001-2004$ & 251 & 26 & \\
\hline $2005-2008$ & 164 & 197 & \\
\hline Histologic grade & & & 0.980 \\
\hline Well & 35 & 14 & \\
\hline Moderate & 360 & 146 & \\
\hline Poor/Undifferentiated & 87 & 37 & \\
\hline Unknown & 58 & 26 & \\
\hline ypT category & & & 0.398 \\
\hline ypT1-2 & 146 & 50 & \\
\hline ypT3 & 367 & 160 & \\
\hline урT4 & 27 & 13 & \\
\hline ypN category & & & 0.795 \\
\hline ypN0 & 339 & 134 & \\
\hline ypN1a & 85 & 34 & \\
\hline ypN1b & 59 & 26 & \\
\hline ypN2a & 36 & 16 & \\
\hline ypN2b & 21 & 13 & \\
\hline ypTNM stage & & & 0.315 \\
\hline ypTNM I & 113 & 36 & \\
\hline ypTNM II & 226 & 98 & \\
\hline ypTNM III & 201 & 89 & \\
\hline Intestinal obstruction & & & 0.834 \\
\hline No & 484 & 201 & \\
\hline Yes & 56 & 22 & \\
\hline HCC risk score & & & 0.503 \\
\hline 1st quartile & 143 & 56 & \\
\hline 2nd quartile & 131 & 45 & \\
\hline 3rd quartile & 152 & 67 & \\
\hline 4th quartile & 114 & 55 & \\
\hline Number of examined lymph node & & & 0.007 \\
\hline$\geq 12$ & 200 & 106 & \\
\hline$<12$ & 340 & 117 & \\
\hline Postoperative radiotherapy & & & 0.001 \\
\hline No & 455 & 208 & \\
\hline Yes & 85 & 15 & \\
\hline
\end{tabular}

Abbreviation: HCC, Hierarchical Condition Categories; No-chemo, without postoperative chemotherapy; 5-FU, 5-fluorouracil. 
Cox proportional hazards models were performed, including all the covariates related to survival. The oxaliplatin group had significantly better OS $(\mathrm{HR}=0.449,95 \% \mathrm{CI}=0.225-0.899, p=0.024$, Table 2$)$ than the 5 -FU group among patients aged $<73$ years, but the difference in OS between the oxaliplatin group and 5 -FU group among patients aged $\geq 73$ years was not significant $(\mathrm{HR}=1.484,95 \% \mathrm{CI}=0.701-3.142$, $p=0.303$, Table 2).

In terms of adverse events, the results in $\mathrm{ypN}+$ patients in relation to age were similar to the results for the entire study population.

\section{Comparison of ypN-oxaliplatin and 5-FU groups}

Univariate analysis of patients with ypNrectal cancer showed that the addition of oxaliplatin did not significantly improve OS (HR $=1.061,95 \%$
$\mathrm{CI}=0.654-1.723, p=0.811$, Supplementary Figure 1) compared with 5-FU alone. Modeling age as a continuous variable, there was no significant interaction between age and efficacy of oxaliplatin in terms of OS ( $p$ for interaction $=0.238)$. The results regarding the effects of age on adverse events were similar in $\mathrm{ypN}-$ patients to those for the study population as a whole.

\section{DISCUSSION}

Patients diagnosed with locally-advanced rectal cancer who have already received preoperative neoadjuvant chemoradiotherapy are recommended for postoperative chemotherapy. However, there is no consensus on whether adding oxaliplatin to 5-FU can improve their prognosis. Hong et al. completed a randomized controlled trial of ADjuvant Oxaliplatin in REctal cancer (ADORE) and demonstrated that postoperative adjuvant FOLFOX improved disease-free
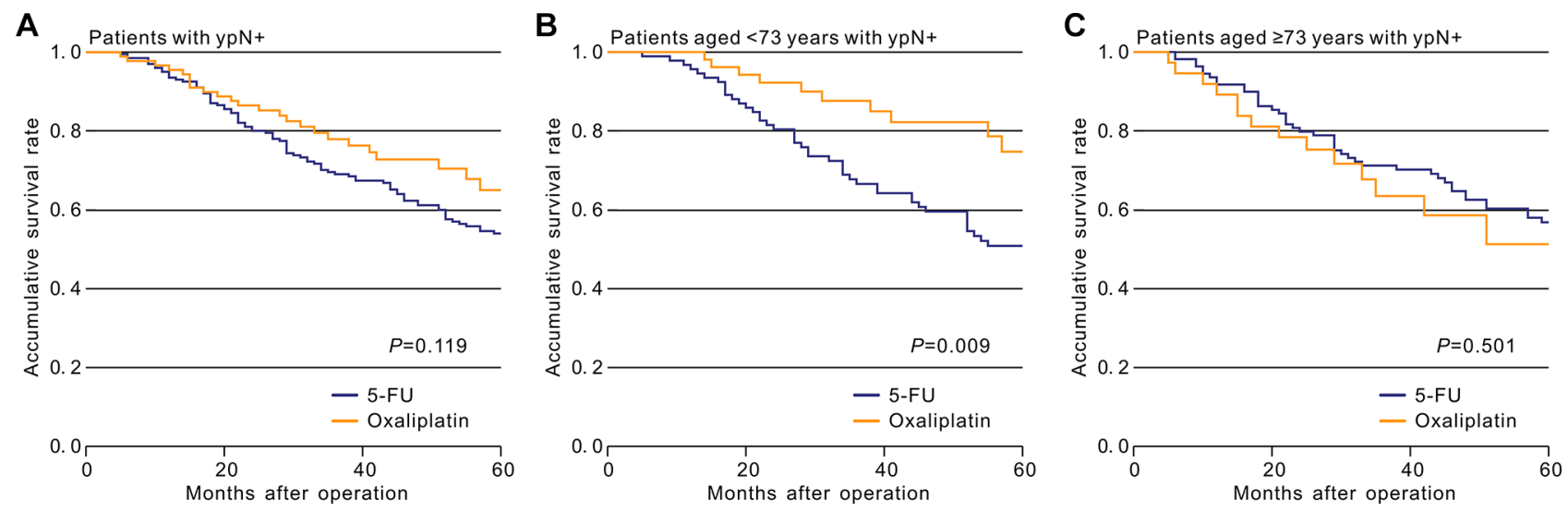

Figure 1: Kaplan-Meier comparison of overall survival among ypN+ patients who received different postoperative treatment. (A) All patients with ypN+; (B) Patients aged <73; (C) Patients aged $\geq 73$.

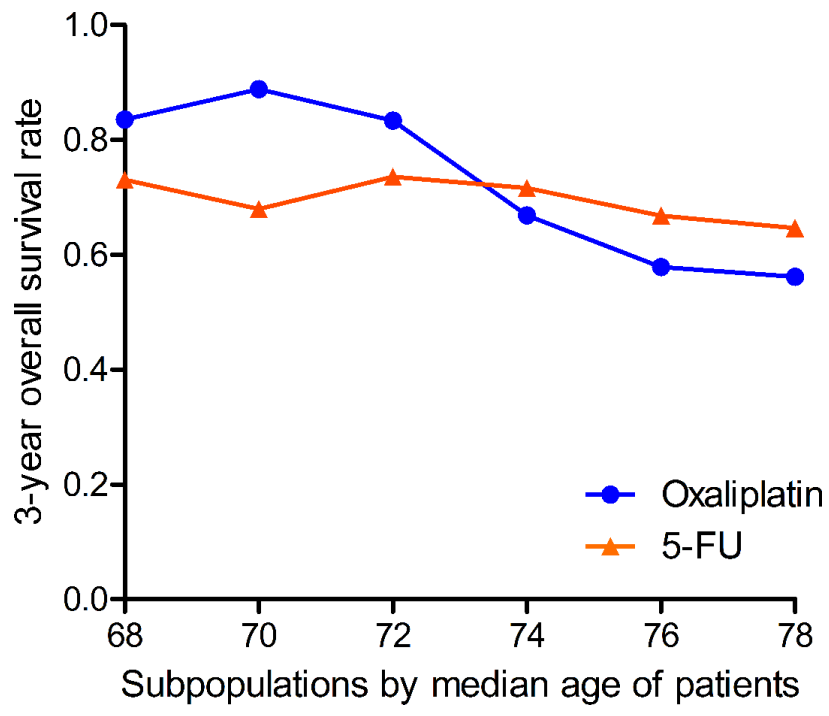

Figure 2: Identification of the impact of age on the efficacy of chemotherapy in terms of overall survival. 
survival compared with fluorouracil plus leucovorin in patients with locally-advanced rectal cancer after preoperative chemoradiotherapy and total mesorectal excision [19]. In contrast, however, Nimeiri et al. performed an updated survival analysis of the randomized ECOG E3201 trial and found no difference in 5-year OS between patients who received 5-FU alone and those who received oxaliplatin-based postoperative chemotherapy [20]. Moreover, our previous analysis of data from the SEER-Medicare database demonstrated that adding oxaliplatin to 5-FU postoperative chemotherapy did not improve cancer-specific survival in patients who received neoadjuvant chemoradiotherapy [21]. However, these previous studies of the efficacy of postoperative chemotherapy in rectal cancer did not consider the impact of age.
The Adjuvant Colon Cancer END-points (ACCENT) group explored the impact of age on efficacy of oxaliplatin-based chemotherapy among patients with colon cancer and proposed that adding oxaliplatin to 5 -FU could improve disease-free survival in patients aged $50-65$ years, while patients aged $\geq 70$ years experienced less benefit from the addition of oxaliplatin [22]. The FOWARC study evaluated preoperative FOLFOX concurrent with radiotherapy and showed higher pathological complete response and down-staging rates than other relevant studies [23]. Meanwhile, FOWARC notably included relatively younger patients (median age, 52 years) than other studies [4, 23-25]. Similarly, elderly patients with rectal cancer are known to be a highly heterogeneous subpopulation for adjuvant chemotherapy,
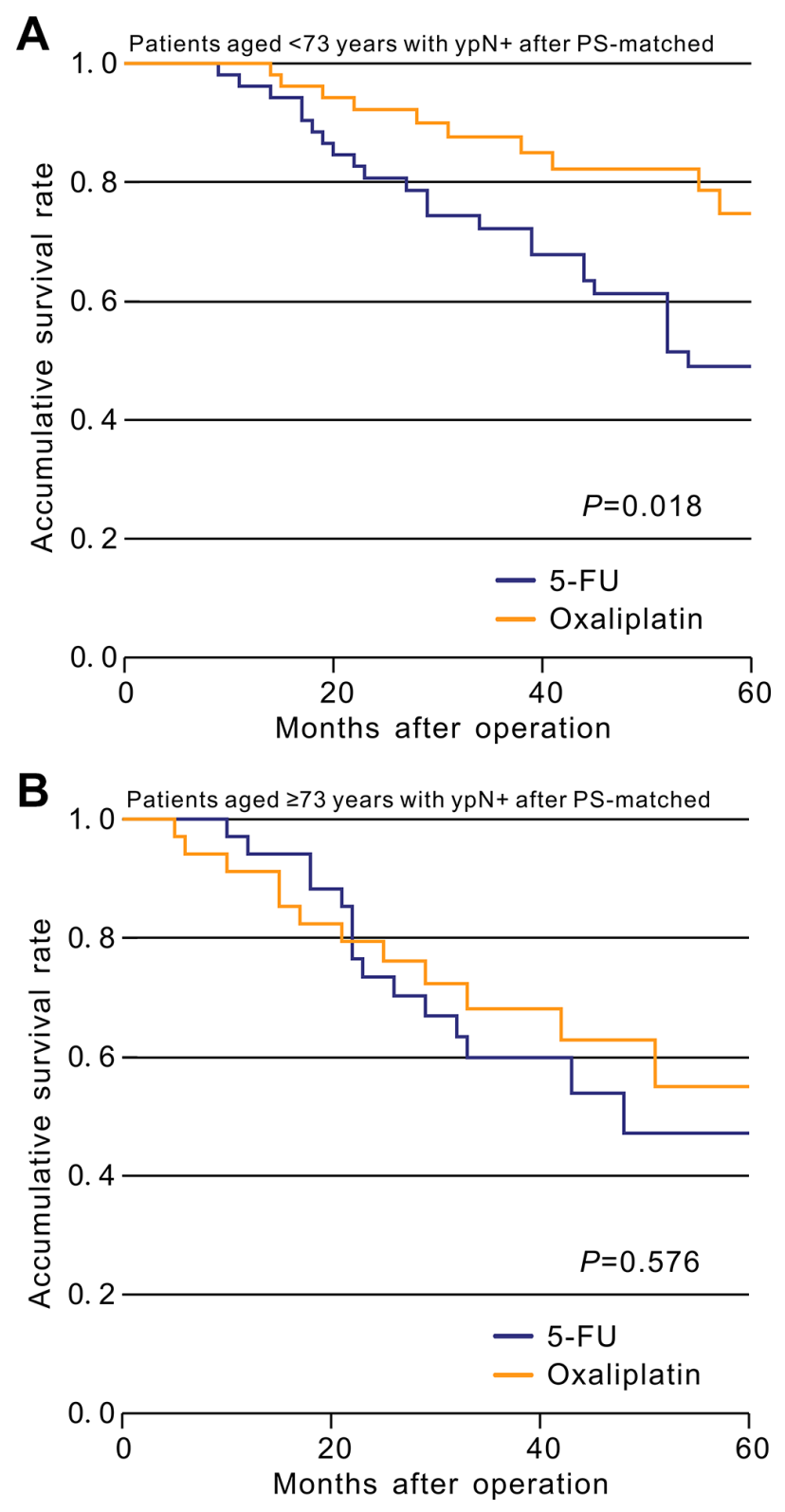

Figure 3: After PS-matched, Kaplan-Meier comparison of overall survival between patients in the 5-FU group and in the oxaliplatin group stratified by age. (A) Patients aged $<73$; (B) Patients aged $\geq 73$. 
Table 2: Cox proportional hazards model for $\mathrm{ypN}+$ patients stratified by age

\begin{tabular}{|c|c|c|c|}
\hline & HR & $95 \% \mathrm{CI}$ & $P$ \\
\hline \multicolumn{4}{|l|}{ Age $<73$ years } \\
\hline \multicolumn{4}{|l|}{ Histologic grade } \\
\hline Well & 1.316 & $0.315-5.503$ & 0.707 \\
\hline Moderate & 1 & & \\
\hline Poor/Undifferentiated & 2.395 & $1.336-4.295$ & 0.003 \\
\hline Unknown & 0.565 & $0.134-2.383$ & 0.437 \\
\hline \multicolumn{4}{|l|}{ Chemotherapy regimens } \\
\hline 5-FU & 1 & & \\
\hline Oxaliplatin & 0.449 & $0.225-0.899$ & 0.024 \\
\hline \multicolumn{4}{|l|}{ Age $\geq 73$ years } \\
\hline \multicolumn{4}{|l|}{ ypN category } \\
\hline ypN1a & 1 & & \\
\hline ypN1b & 0.951 & $0.444-2.036$ & 0.898 \\
\hline ypN2a & 1.818 & $0.940-3.516$ & 0.076 \\
\hline ypN2b & 3.217 & $1.484-6.974$ & 0.003 \\
\hline \multicolumn{4}{|l|}{ Year of diagnosis } \\
\hline $1992-1996$ & 39.044 & 4.084-373.260 & 0.001 \\
\hline $1997-2000$ & 2.237 & $0.944-5.304$ & 0.068 \\
\hline 2001-2004 & .920 & $0.451-1.878$ & 0.820 \\
\hline 2005-2008 & 1 & & \\
\hline \multicolumn{4}{|l|}{ HCC risk score } \\
\hline 1st quartile & 1 & & \\
\hline 2nd quartile & 0.661 & $0.303-1.441$ & 0.298 \\
\hline 3rd quartile & 0.780 & $0.347-1.756$ & 0.548 \\
\hline 4th quartile & 2.361 & $1.206-4.624$ & 0.012 \\
\hline \multicolumn{4}{|l|}{ Chemotherapy regimens } \\
\hline $5-\mathrm{FU}$ & 1 & & \\
\hline Oxaliplatin & 1.484 & $0.701-3.142$ & 0.303 \\
\hline
\end{tabular}

Abbreviation: 5-FU, 5-fluorouracil; CI, Confidential intervals; HCC, Hierarchical Condition Categories.

with a high incidence of comorbidities, and many studies have therefore excluded this subpopulation, or it has only comprised a small percent of the overall study population. Indeed, the ADORE trial included patients with a median age of 55 years, and only $55(17 \%)$ patients were aged $\geq 65$ years, making it inappropriate to extrapolate the conclusions to elderly patients [19]. In contrast, our previous study analyzed patients aged $\geq 66$ years from the SEER-Medicare database [21]. It is therefore possible that the apparent discrepancies between the results may be attributable to differences in patient age, and that the efficacy of chemotherapy may be age-dependent.

To the best of our knowledge, the present study was the first to explore the effect of age on the efficacy of adjuvant oxaliplatin-based chemotherapy. Although the differences did not reach statistical significance in a crude analysis of data for rectal cancer patients, our results nevertheless indicated that the efficacy of adding oxaliplatin to 5-FU was reversed at a specific age point. Several previous studies have reported that postoperative pathologic stage could accurately estimate prognosis and thus play an important role in clinical decision making in terms of the use and efficacy of postoperative chemotherapy [26-28]; however, postoperative chemotherapy is recommended by the NCCN Clinical Practice Guidelines regardless of the postoperative pathological results [7]. We therefore conducted a detailed analysis stratified by ypTNM stage (ypN + and $y p N-)$ to explore the relationship between chemotherapy efficacy and age using the STEPP method. Tests for interaction showed that patient age could play an important role in predicting the efficacy of chemotherapy, and indicated that, 
compared with 5-FU alone, adding oxaliplatin to 5-FU could prolong survival in ypN + patients aged $<73$ years, but did not translate into significant survival benefits in ypN + patients aged $\geq 73$ (Figure 2,3 ), in accord with the results of a study evaluating age and chemotherapy in colon cancer [22]. However, oxaliplatin did not significantly improve survival in ypN- patients regardless of age, and a test for interaction showed that age had no effect on the lack of survival benefits. The stability of our results was confirmed by PS-matched analysis (Figure 3) and Cox proportional hazards model (Table 2).

Several previous studies reported that the use of adjuvant chemotherapy would decrease with increasing patient age [29, 30], mainly because clinicians considered that the high comorbidity and poor performance status in older patients would have a negative influence on survival [31]. However, although several studies have demonstrated that patient age may be an important factor for predicting prognosis in patients with rectal cancer, no specific studies have evaluated the impact of age on the efficacy of adjuvant chemotherapy in rectal cancer patients who have already received preoperative neoadjuvant chemoradiotherapy. Moreover, the NCCN Clinical Practice Guidelines for Older Adult Oncology provide no detailed evidence or clinical decision-making strategies regarding postoperative chemotherapy for elderly patients with rectal cancer [11]. Further evidence is therefore needed to validate the decreased use of adjuvant chemotherapy in elderly patients. Furthermore, there is no consistent definition of elderly age for patients with rectal cancer. The results of the current study suggest that the selection of adjuvant chemotherapy should be based on patient age, and STEPP analysis indicated a cut-off of age for oxaliplatin-based chemotherapy of 73 years, as confirmed by Cox proportional hazards model analysis. In addition, however, the impact of age on adjuvant chemotherapy differed according to postoperative pathologic stage, with patient age impacting on the efficacy of adjuvant chemotherapy in $\mathrm{ypN}+$, but not $\mathrm{ypN}-$ patients. It is possible that a survival benefit was difficult to detect among $\mathrm{ypN}-$ patients treated with adjuvant chemotherapy because of their better rate of survival without chemotherapy, making it harder to detect an improvement [8]. We also found that $\mathrm{ypN}+$ patients aged $\geq 73$ years in the 4 th quartile of HCC risk had poorer prognoses than those in the 1st quartile, indicating that a high $\mathrm{HCC}$ risk score was a risk factor. These results suggest that decisions regarding adjuvant chemotherapy should not be made on the basis of patient age alone, and further studies are urgently needed to explore the need for careful assessment of performance status, comorbidities, treatment risks, and life expectancy in the selection of optimal treatment modalities.

Chemotherapy-related adverse events are a concern in clinical practice. Our study showed that adding oxaliplatin to 5-FU could increase the incidence of adverse effects compared with 5-FU alone in terms of neutropenia, nausea or vomiting, dehydration, and thrombocytopenia. Adverse events were also more common in elderly patients who received oxaliplatin compared with younger patients (i.e., acute renal failure, infection, nausea or vomiting, dehydration, diarrhea, thrombocytopenia, ischemic heart disease, congestive heart failure, and cardiac dysrhythmia), indicating that the incidence of adverse events was age related, consistent with other studies [32, 33]. Age-related adverse events may thus mask or impact on the efficacy of oxaliplatin regimens in elderly subpopulations. Further large-scale, high-quality studies are needed to evaluate the impact of age on adverse events, and to improve patient selection for individual chemotherapy.

Several limitations of the present study should be addressed. First, this was a retrospective study, and despite the use of both PS-matched analysis and Cox proportional hazards model to account for known relevant confounding factors, we could not eliminate the possibility of other potential confounding factors that might have affected the use and efficacy of chemotherapy. Second, the data on adjuvant chemotherapy was from fee-for-service insurance using a "one-claim" algorithm, which may have influenced the representative nature of the included patients, resulting in heterogeneity $[34,35]$. Third, our study could not determine how aggressively to treat patients such that the survival benefits from chemotherapy would outweigh the costs and risks. Furthermore, clinical treatment patterns may differ between younger and more elderly patients, and these differences may limit the applicability of the results to the overall rectal cancer population. Future studies are needed to determine the subpopulations of younger and more elderly patients who may derive survival benefit from adjuvant chemotherapy.

In conclusion, the addition of oxaliplatin to 5-FU chemotherapy could prolong OS in rectal cancer patients with prior neoadjuvant chemoradiotherapy and curative resection aged $<73$ years with ypN + status, but not in $\mathrm{ypN}+$ patients aged $\geq 73$ years, or in ypN- patients, irrespective of age.

\section{MATERIALS AND METHODS}

\section{Ethics statement}

The Permission to access the research data file in Surveillance, Epidemiology, and End Results (SEER)-Medicare program was obtained by the authors and (reference no. D6-MEDIC-821). All data were masked and no protected health information could be linked to individual patients. The study was approved by the Institutional Review Board of the First Hospital of China Medical University (reference no. [2012] 96).

\section{Data source}

This study utilized data from the Surveillance, Epidemiology, and End Results (SEER)-Medicare 
database, based on collaboration among the SEER registries, the National Cancer Institute, and the Centers for Medicare and Medicaid Services, and which provides patient data through linkage of population-based SEER and Medicare claims data. The SEER program contains information on cancer patient demographics, tumor characteristics, cancer-related treatments, and cause of death, and includes approximately $28 \%$ of the US population [36]. Part A of Medicare comprises health-insurance data for approximately $97 \%$ of the US population aged $\geq 65$ years, covering hospitals, skillednursing facilities, hospices, and home health care, while Part B comprises approximately $96 \%$ of beneficiaries, covering physician and outpatient services [37, 38].

\section{Eligible patient selection}

The inclusion criteria for eligible patients were as follows: (1) aged $\geq 66$ years who were diagnosed with primary rectal (SEER cancer site codes: 19.9 and 20.9) adenocarcinoma (SEER histology codes: 8000-8152, 8154-8231, 8243-8245, 8250-8576, 8940-8950, and 8980-8981) from 1992-2008; (2) underwent primary tumor resection with curative intent within 180 days of diagnosis; (3) received preoperative neoadjuvant therapy involving radiotherapy plus 5-FU or capecitabine recommended by $\mathrm{NCCN}$; (4) received postoperative chemotherapy within 120 days of operation (5-FU group included all patients who received 5-FU or capecitabine alone, the oxaliplatin group included all patients who received 5-FU and leucovorin plus oxaliplatin or capecitabine plus oxaliplatin within 30 days of their first chemotherapy dose). The detailed drug codes based on National Drug Code and Health Care Financing Administration Common Procedure Coding System have been reported previously [21].

The exclusion criteria for patients were: (1) diagnosed with in situ tumor (yp stage 0: Tis N0 M0) because of the small sample size; (2) history of prior nonrectal cancer or diagnosis of non-rectal cancer 1 year after rectal cancer diagnosis; (3) received other postoperative chemotherapy regimens; (4) died during the immediate postoperative period (within 30 days); (5) incomplete pathological stage entries or diagnostic data; (6) diagnosed with pTxNxMx, because of inaccuracy of the data in the SEER-Medicare database; and (7) membership of a Medicare-sponsored health maintenance organization or lack of enrollment in Medicare Parts A and B from 12 months before through to 9 months after diagnosis.

\section{Study variables}

Patient demographic characteristics including age and year at diagnosis, sex, race, geographic region, marital status, and socioeconomic status (household income and education level) were obtained from the SEER patient entitlement and diagnosis summary file. Socioeconomic status was used to summarize the median household income at census tract level and the percentage of people aged $\geq 25$ years with $<12$ years of education.

Disease characteristics including tumor stage, tumor grade, histological type, and comorbidity were analyzed. Postoperative pathological stage (ypTNM) was identified based on the seventh edition of the Union for International Cancer Control or American Joint Committee on Cancer tumor-node-metastasis (TNM) staging system [39, 40]. To control for the effects of comorbidities, analyses were adjusted according to the Centers for Medicare and Medicaid Services Hierarchical Condition Category (HCC) based on Medicare inpatient and outpatient claims for various comorbidities within the 12 months before rectal cancer diagnosis, where the HCC risk score summarizes the health care problems and predicts the future health care cost of a population compared with the average Medicare beneficiary $(\mathrm{HCC}=1.0)$ [41]. In the current study, HCC risk score, calculated based on patient demographics and diagnostic profiles using software provided by the Centers for Medicare and Medicaid Services, was used to reflect the health conditions of the patients [42]. We also identified chemotherapy-related adverse events by assessing discharge diagnoses within 6 months of chemotherapy initiation. To avoid the effects of prediagnosis disease conditions on chemotherapyrelated adverse events, disease conditions occurring in the 12 months before cancer diagnosis were not identified as adverse events. International Classification of Diseases, 9th Revision, Clinical Modification (ICD-9-CM) diagnostic codes was used to classify chemotherapyrelated adverse events.

\section{Statistical analysis}

Categorical variables were compared using $\chi^{2}$ test. Kaplan-Meier survival analysis and log-rank tests were used to compare overall survival (OS) between different chemotherapy groups. Subpopulation treatment effect pattern plot (STEPP) analysis was used to examine the relationship between treatment effect and the covariate of interest (i.e., age) and to validate the age-related cut-off points for treatment effects by estimating the treatment effects for a sequence of subpopulations, where the subpopulations corresponded to age values [43-45]. Multivariate analyses were performed using Cox proportional hazards models including all significant survival-related variables in univariate analysis.

In clinical practice, there were several significant differences between patients treated with or without chemotherapy, particularly in terms of comorbidities and age. We therefore used propensity score (PS)-matched analysis to deal with the selection bias caused by nonrandom assignment and to compare treatment effects [46-48]. Each patient's probability of 
receiving oxaliplatin or 5-FU depending on the covariates in each group was estimated by logistic regression models. Unexposed PS-matched cohorts with a balance of covariates and equivalent mean PS across treatment groups were generated and log-rank tests were applied to these PS-matched cohorts.

All statistical analyses were performed using R, version 3.1.1 (R Foundation for Statistical Computing, Vienna, Austria), STATA version 12.0 (Stata Corporation, College Station, TX, USA), SAS version 9.3 (SAS Institute, Cary, NC, USA), and PASW Statistics version 18.0 (SPSS, Inc., Somers, NY, USA). A two-sided $p$ value $<0.05$ was considered statistically significant for all analyses.

\section{ACKNOWLEDGMENTS AND FUNDING}

This work was supported by National Science Foundation of China (No.81201888, 81372549 and No. 81172370), The Special Prophase Program for National Key Basic Research Program of China (No.2014CB560712) and Clinical Capability Construction Project for Liaoning Provincial Hospitals (LNCCC-A01-2014).

\section{Abbreviations}

ACCENT: Adjuvant Colon Cancer End-Points; ADORE: ADjuvant Oxaliplatin in REctal cancer; CIs: confidence intervals; HCC: Hierarchical Condition Category; HR: hazard ratio; ICD-9-CM: International Classification of Diseases, 9th Revision, Clinical Modification; NCCN: National Comprehensive Cancer Network; OS: overall survival; PS: propensity score; SEER: Surveillance, Epidemiology, and End Results; STEPP: Subpopulation treatment effect pattern plot; TNM: tumor-node-metastasis; ypN+: positive lymph nodes; 5-FU: 5-fluorourcil.

\section{CONFLICTS OF INTEREST}

All authors declare that they have no competing interests.

\section{REFERENCES}

1. Torre LA, Bray F, Siegel RL, Ferlay J, Lortet-Tieulent J, Jemal A. Global cancer statistics, 2012. CA Cancer J Clin. 2015; 65:87-108.

2. van Gijn W, Marijnen CA, Nagtegaal ID, Kranenbarg EM, Putter H, Wiggers T, Rutten HJ, Pahlman L, Glimelius B, van de Velde CJ, Dutch Colorectal Cancer G. Preoperative radiotherapy combined with total mesorectal excision for resectable rectal cancer: 12-year follow-up of the multicentre, randomised controlled TME trial. The Lancet Oncology. 2011; 12:575-582.
3. Kapiteijn E, Marijnen CA, Nagtegaal ID, Putter H, Steup WH, Wiggers T, Rutten HJ, Pahlman L, Glimelius B, van Krieken JH, Leer JW, van de Velde CJ, Dutch Colorectal Cancer G. Preoperative radiotherapy combined with total mesorectal excision for resectable rectal cancer. The New England journal of medicine. 2001; 345:638-646.

4. Rodel C, Liersch T, Becker H, Fietkau R, Hohenberger W, Hothorn T, Graeven U, Arnold D, Lang-Welzenbach M, Raab HR, Sulberg H, Wittekind C, Potapov S, et al. Preoperative chemoradiotherapy and postoperative chemotherapy with fluorouracil and oxaliplatin versus fluorouracil alone in locally advanced rectal cancer: initial results of the German CAO/ARO/AIO-04 randomised phase 3 trial. The Lancet Oncology. 2012; 13:679-687.

5. Yeo HL, Paty PB. Management of recurrent rectal cancer: practical insights in planning and surgical intervention. Journal of surgical oncology. 2014; 109:47-52.

6. van der Pool AE, de Wilt JH, Lalmahomed ZS, Eggermont AM, Ijzermans JN, Verhoef C. Optimizing the outcome of surgery in patients with rectal cancer and synchronous liver metastases. The British journal of surgery. 2010; 97:383-390.

7. Rectal cancer V.2. NCCN Clinical Practical Guidelines in Oncology. [http://wwwncenorg/professionals/physician_ gls/f_guidelinesasp]. 2015.

8. Neugut AI, Fleischauer AT, Sundararajan V, Mitra N, Heitjan DF, Jacobson JS, Grann VR. Use of adjuvant chemotherapy and radiation therapy for rectal cancer among the elderly: a population-based study. Journal of clinical oncology. 2002; 20:2643-2650.

9. Cai X, Wu H, Peng J, Zhu J, Cai S, Cai G, Zhang Z. Tolerability and outcomes of radiotherapy or chemoradiotherapy for rectal cancer in elderly patients aged 70 years and older. Radiation oncology (London, England). 2013; 8:86.

10. Cafiero F, Gipponi M, Lionetto R, Group PARCS. Randomised clinical trial of adjuvant postoperative RT vs. sequential postoperative RT plus 5-FU and levamisole in patients with stage II-III resectable rectal cancer: a final report. Journal of surgical oncology. 2003; 83:140-146.

11. Older Adult Oncology V.1. NCCN Clinical Practical Guidelines in Oncology. [http://wwwnccnorg/professionals/ physician_gls/f_guidelinesasp]. 2015.

12. Lewis JH, Kilgore ML, Goldman DP, Trimble EL, Kaplan R, Montello MJ, Housman MG, Escarce JJ. Participation of patients 65 years of age or older in cancer clinical trials. Journal of clinical oncology. 2003; 21:1383-1389.

13. Townsley CA, Selby R, Siu LL. Systematic review of barriers to the recruitment of older patients with cancer onto clinical trials. Journal of clinical oncology. 2005; 23:3112-3124.

14. Shahir MA, Lemmens VE, van de Poll-Franse LV, Voogd AC, Martijn H, Janssen-Heijnen ML. Elderly patients with rectal cancer have a higher risk of treatment-related complications and a poorer prognosis than younger patients: a population- 
based study. European journal of cancer (Oxford, England : 1990). 2006; 42:3015-3021.

15. Jung B, Pahlman L, Johansson R, Nilsson E. Rectal cancer treatment and outcome in the elderly: an audit based on the Swedish Rectal Cancer Registry 1995-2004. BMC cancer. 2009; 9:68.

16. Gross CP, McAvay GJ, Krumholz HM, Paltiel AD, Bhasin D, Tinetti ME. The effect of age and chronic illness on life expectancy after a diagnosis of colorectal cancer: implications for screening. Annals of internal medicine. 2006; 145:646-653.

17. Lemmens VE, Janssen-Heijnen ML, Verheij CD, Houterman S, Repelaer van Driel OJ, Coebergh JW. Co-morbidity leads to altered treatment and worse survival of elderly patients with colorectal cancer. The British journal of surgery. 2005; 92:615-623.

18. Schiphorst AH, Verweij NM, Pronk A, Hamaker ME. Agerelated guideline adherence and outcome in low rectal cancer. Diseases of the colon and rectum. 2014; 57:967-975.

19. Hong YS, Nam BH, Kim KP, Kim JE, Park SJ, Park YS, Park JO, Kim SY, Kim TY, Kim JH, Ahn JB, Lim SB, Yu CS, et al. Oxaliplatin, fluorouracil, and leucovorin versus fluorouracil and leucovorin as adjuvant chemotherapy for locally advanced rectal cancer after preoperative chemoradiotherapy (ADORE): an open-label, multicentre, phase 2, randomised controlled trial. The Lancet Oncology. 2014; 15:1245-1253.

20. Nimeiri HS, Feng Y, Catalano PJ, Meropol NJ, Giantonio BJ, Sigurdson ER, Martenson JA, Whitehead RP, Sinicrope FA, Mayer RJ, O'Dwyer PJ, Benson AB, Eastern Cooperative Oncology Group. Intergroup randomized phase III study of postoperative irinotecan, 5-fluorouracil, and leucovorin versus oxaliplatin, 5-fluorouracil, and leucovorin versus 5 -fluorouracil and leucovorin for patients with stage II or III rectal cancer receiving either preoperative radiation and 5-fluorouracil or postoperative radiation and 5-fluorouracil: ECOG E3201-An updated survival analysis. Journal of clinical oncology. 2013; 31:e14711.

21. Gao P, Song YX, Sun JX, Chen XW, Xu YY, Zhao JH, Huang $\mathrm{XZ}$, Xu HM, Wang ZN. Which is the best postoperative chemotherapy regimen in patients with rectal cancer after neoadjuvant therapy? BMC cancer. 2014; 14:888.

22. McCleary NJ, Meyerhardt JA, Green E, Yothers G, de Gramont A, Van Cutsem E, O'Connell M, Twelves CJ, Saltz LB, Haller DG, Sargent DJ. Impact of age on the efficacy of newer adjuvant therapies in patients with stage II/III colon cancer: findings from the ACCENT database. Journal of clinical oncology. 2013; 31:2600-2606.

23. Deng Y, Chi P, Lan P, Wang L, Cui L, Chen D, Cao J, Wei H, Peng X, Huang Z, Cai G, Zhao R, Huang Z, et al. A multicenter randomized controlled trial of mFOLFOX6 with or without radiation in neoadjuvant treatment of local advanced rectal cancer (FOWARC study): Preliminary results. Journal of clinical oncology. 2015; 33:3500.
24. Aschele C, Cionini L, Lonardi S, Pinto C, Cordio S, Rosati G, Artale S, Tagliagambe A, Ambrosini G, Rosetti P, Bonetti A, Negru ME, Tronconi MC, et al. Primary tumor response to preoperative chemoradiation with or without oxaliplatin in locally advanced rectal cancer: pathologic results of the STAR-01 randomized phase III trial. Journal of clinical oncology. 2011; 29:2773-2780.

25. Rodel C, Graeven U, Fietkau R, Hohenberger W, Hothorn T, Arnold D, Hofheinz RD, Ghadimi M, Wolff HA, Lang-Welzenbach M, Raab HR, Wittekind C, Strobel P, et al. Oxaliplatin added to fluorouracil-based preoperative chemoradiotherapy and postoperative chemotherapy of locally advanced rectal cancer (the German CAO/ARO/ AIO-04 study): final results of the multicentre, open-label, randomised, phase 3 trial. The Lancet Oncology. 2015.

26. Quah HM, Chou JF, Gonen M, Shia J, Schrag D, Saltz LB, Goodman KA, Minsky BD, Wong WD, Weiser MR. Pathologic stage is most prognostic of disease-free survival in locally advanced rectal cancer patients after preoperative chemoradiation. Cancer. 2008; 113:57-64.

27. Haynes AB, You YN, Hu CY, Eng C, Kopetz ES, Rodriguez-Bigas MA, Skibber JM, Cantor SB, Chang GJ. Postoperative chemotherapy use after neoadjuvant chemoradiotherapy for rectal cancer: Analysis of Surveillance, Epidemiology, End Results-Medicare data, 1998-2007. Cancer. 2014; 120:1162-1170.

28. Moon SH, Kim DY, Park JW, Oh JH, Chang HJ, Kim SY, Kim TH, Park HC, Choi DH, Chun HK, Kim JH, Park JH, Yu CS. Can the new American Joint Committee on Cancer staging system predict survival in rectal cancer patients treated with curative surgery following preoperative chemoradiotherapy? Cancer. 2012; 118:4961-4968.

29. Guillerme F, Clavier JB, Nehme-Schuster H, Leroy V, Heitz D, Schumacher C, Abdelghani MB, Brigand C, Kurtz JE, Noel G. Age impacts the pattern of care for elderly patients with rectal cancer. International journal of colorectal disease. 2014; 29:157-163.

30. Ayanian JZ, Zaslavsky AM, Fuchs CS, Guadagnoli E, Creech CM, Cress RD, O'Connor LC, West DW, Allen ME, Wolf RE, Wright WE. Use of adjuvant chemotherapy and radiation therapy for colorectal cancer in a populationbased cohort. Journal of clinical oncology. 2003; 21:1293-1300.

31. Chang GJ, Skibber JM, Feig BW, Rodriguez-Bigas M. Are we undertreating rectal cancer in the elderly? An epidemiologic study. Annals of surgery. 2007; 246:215-221.

32. Cen P, Liu C, Du XL. Comparison of toxicity profiles of fluorouracil versus oxaliplatin regimens in a large population-based cohort of elderly patients with colorectal cancer. Annals of oncology. 2012; 23:1503-1511.

33. Shankaran V, Mummy D, Koepl L, Blough D, Yim YM, Yu E, Ramsey S. Adverse events associated with bevacizumab and chemotherapy in older patients with metastatic colorectal cancer. Clinical colorectal cancer. 2013; 12:204-213 e201. 
34. Bradley CJ, Given CW, Dahman B, Fitzgerald TL. Adjuvant chemotherapy after resection in elderly Medicare and Medicaid patients with colon cancer. Archives of internal medicine. 2008; 168:521-529.

35. Dobie SA, Baldwin LM, Dominitz JA, Matthews B, Billingsley K, Barlow W. Completion of therapy by Medicare patients with stage III colon cancer. Journal of the National Cancer Institute. 2006; 98:610-619.

36. Institute NC. Surveillance, Epidemiology, and End Results Program. [http://seercancergov/indexhtml].

37. Potosky AL, Riley GF, Lubitz JD, Mentnech RM, Kessler LG. Potential for cancer related health services research using a linked Medicare-tumor registry database. Medical care. 1993; 31:732-748.

38. SEER-Medicare Linked Database. [http://healthcaredelivery cancergov/seermedicare/].

39. Edge SB BD, Compton CC, Fritz AG, Greene FL, Trotti A. AJCC cancer staging manual. 7th ed. New York: Springer. 2010.

40. Sobin LH GM, Wittekind C. UICC: TNM classification of malignant tumours, 7th ed. Oxford: Wiley-Blackwell. 2009.

41. Ash AS, Ellis RP, Pope GC, Ayanian JZ, Bates DW, Burstin H, Iezzoni LI, MacKay E, Yu W. Using diagnoses to describe populations and predict costs. Health care financing review. 2000; 21:7-28.
42. CMS.gov 2012 Model Software/ICD-9-CM Mappings. [https://wwwcmsgov/Medicare/Health-Plans/

MedicareAdvtgSpecRateStats/Risk-Adjustors-Items/ Risk2012html].

43. Bonetti M, Gelber RD. A graphical method to assess treatmentcovariate interactions using the Cox model on subsets of the data. Statistics in medicine. 2000; 19:2595-2609.

44. Bonetti M, Zahrieh D, Cole BF, Gelber RD. A small sample study of the STEPP approach to assessing treatmentcovariate interactions in survival data. Statistics in medicine. 2009; 28:1255-1268.

45. Bonetti M, Gelber RD. Patterns of treatment effects in subsets of patients in clinical trials. Biostatistics. 2004; $5: 465-481$.

46. Rubin DB. Estimating causal effects from large data sets using propensity scores. Annals of internal medicine. 1997; 127:757-763.

47. Rubin DB, Thomas N. Matching using estimated propensity scores: relating theory to practice. Biometrics. 1996; 52:249-264.

48. D'Agostino RB, Jr. Propensity score methods for bias reduction in the comparison of a treatment to a non-randomized control group. Statistics in medicine. 1998; 17:2265-2281. 